\title{
AWARENESS AND ATTITUDE TOWARDS MASS DISASTER AND ITS MANAGEMENT AMONG HOUSE SURGEONS IN A DENTAL COLLEGE AND HOSPITAL IN CHENNAI, INDIA
}

\author{
SRI SAKTHI DORAI KANNAN, VYSHIALI SIVARAM KUMAR, PRADEEP KUMAR RATHINAVELU \& \\ MEIGNANA ARUMUGHAM INDIRAN \\ Saveetha Dental College, Saveetha University, India
}

\begin{abstract}
More than 2.6 billion people were affected by mass disasters in the last decade, which lead to mass casualties that can overwhelm local medical resources and prevent them from delivering comprehensive and definitive medical care. Awareness and training towards disaster management is essential for all in the health care delivery sector. India, has been vulnerable to natural disasters and manmade disasters from time to time. Being the second populous country in the world and dental surgeons forming a significant portion of an untapped health resource, assessment of awareness and attitude towards a mass disaster management would serve as valuable data in reforming dental curriculum and future training. Hence, the current study was done to determine the awareness and attitude towards mass disaster among house surgeons in a dental college and hospital in Chennai, India. This cross-sectional study was conducted with a 17-item pretested, self-administered questionnaire. The Cronbach's alpha and split validity scores for the questionnaire were 0.8 and 0.9 respectively. The final sample size was 132, after adjusting for a non-response rate of 10 percent. 128 house surgeons participated in the study, (response rate - 95\%). About $34.4 \%$ had good knowledge and $68.8 \%$ had a positive attitude towards mass disaster and its management. A positive Spearman's correlation was found between knowledge and attitude scores. Although knowledge was not satisfactory, the house surgeons had a positive attitude towards the public health issue in question. About $72 \%$ were prepared to undergo proper training and $77 \%$ felt disaster training should be part of any internship program.
\end{abstract}

Keywords: mass disaster, disaster management, dental professionals, dental house surgeons.

\section{INTRODUCTION}

In the period of past ten years, more than 2.6 billion people have become casualties of natural disasters [1]. The United Nations Department of Humanitarian Affairs defines disaster as a situation or event that "overwhelms local capacity, necessitating a request to a national or international level for external assistance" [2]. Disasters are categorized as natural disasters such as floods, earthquakes, hurricanes, and tornadoes; or manmade disasters such as chemical, biological, radiological, nuclear, and explosive (CBRNE) events.

In India, $80 \%$ of the area is vulnerable to natural disasters. On the whole, $58.6 \%$ of the landmass is at risk of earthquakes and $12 \%$ of it is subject to floods and river erosion. Of the $7516 \mathrm{~km}$ long coastline, approximately $5700 \mathrm{~km}$ is at risk from cyclones and tsunamis; $68 \%$ of the cultivatable area is vulnerable to drought; and hilly areas are at risk from landslides and avalanches. On the other hand, India has also faces more terrorist activities [3].

The occurrences have brought to light the deficiency in disaster preparedness and actions by healthcare delivery system in India. The Government of India has newly released the "Standard Operating Procedures for Responding to Natural Disasters (2010)" [4]. 
Integrating other healthcare professionals like dental professionals might significantly improve the disaster management capabilities in India.

Disasters in any form are dangerous to the health and welfare of all civilized societies. Disasters disrupt the progress of an entire nation and are capable of destroying the accomplishments of developmental efforts, often pushing nations in pursuit of progress back by several decades.

Accelerated flawless and coordinated response during the times of emergencies is very important in any disaster situation [5], and manpower scarcity can be serious block for the same. The best way to handle this manpower shortage is by involving healthcare professionals other than the traditional medical practitioners. This includes a wide array of health professionals like dental professionals who are highly skilled that can contribute to efficient disaster management [6]. As being a part of the healthcare delivery system, dentists have obvious ethical considerations regarding their contribution in disaster management.

Although dentists constitute an important aspect of health team, their capacity has not been stressed. Dentists can successfully coordinate with the emergency medical response system in building needed partnerships, identifying and collect resources, and facilitating training, policy development, surveillance, and evaluation [7]. Since dentists are distributed throughout a community they can also be a part of effective surveillance network [8].

Based on the extensive academic training and practical skills, dentists can succeed in performing various roles ranging from forensic activities to treating orofacial injuries, controlling infection, extracting information from medical histories, administering injections, suturing wounds, developing immunization procedures, prescribing drugs, providing triage services, and providing public information [6], [9]-[14]. These qualities thus strengthen the role that dental professionals can play a major role in disaster preparedness and management. Rekow et al. [10] and Galligan et al. [15] have observed that dental professionals might represent a resource that is available but not utilized and neglected.

At present, the information on the readiness of dental professionals to respond to disasters has been limited. Colvard et al. [16] have reported that Illinois dentists required minimal additional training to render their services as dental emergency responders. In addition, Rajesh et al. [17] have reported that Indian dental postgraduates had high attitude but low knowledge and behaviour scores regarding disaster management.

Mobilizing dentists for disaster management has the possibility to be enormously helpful, as they are widely distributed within the communities, similar to medical personnel.

At present, the total number of dental institutions in India is 301, and the number of students completing a bachelor of dental surgery in 1 year is 23,690 [18]. This constitutes a vast number of healthcare professionals who can be of crucial help during the times of emergencies. These numbers indicate that there is an adequate potential resource pool which has to be managed properly to respond during mass disasters in developing countries like India.

To our knowledge, a very limited number of studies have discussed the role of dental house surgeons in disaster preparedness and management in India. Information about knowledge, attitude, and behaviour among dental house surgeon might provide valuable information for policy makers and administrators. It will also provide baseline information that might be helpful for incorporating disaster management in dental undergraduate curriculum in India. It might eventually serve the way for efficient disaster preparedness and responses in India. A program called as the 'National Disaster Life Support' (NDLS) 
training program can also be developed to better prepare health care professionals and emergency response personnel for mass casualty events [19]. Therefore, the aim of the present study is to determine the awareness and attitude towards mass disaster among house surgeons in a dental college and hospital in Chennai, India.

\section{MATERIALS AND METHODS}

\subsection{Study area}

Chennai, the capital city of Tamil Nadu state in India has a diverse population of around 4.3 million. It is a major cultural, economic and educational centre in South India. Chennai has an umpteen number of dental clinics, dental speciality centres and over a dozen dental colleges producing an estimated thousand dental graduates every year. Awareness and training towards disaster management is essential for all in the health care delivery sector. India has been vulnerable to natural disasters and manmade disasters from time to time. Being the second most populated country in the world and dental surgeons forming a significant portion of an untapped health resource, assessment of awareness and attitude towards a mass disaster management would serve as a valuable data in reforming dental curriculum and future training. However, a very limited number of studies have been conducted so far to assess the awareness and attitude towards mass disaster and its management among house surgeons in a dental college.

\subsection{Study population}

A list of house surgeons practicing in Saveetha dental college, Chennai was obtained from the university administration office. There were totally 140 dental house surgeons in the college hospital. Self-administered questionnaire was distributed to 132 house surgeons.

\subsection{Inclusion criteria}

Dental house surgeons studying in Saveetha dental college.

\subsection{Exclusion criteria}

Dental house surgeons who are not willing to participate in the study. Dental house surgeons who were unavailable even after three consecutive visits to the posted department.

\subsection{Ethical clearance}

Prior to the start of the study ethical clearance was obtained from the institutional Ethics Committee, Saveetha University. Written informed consent was obtained from the study participants (Annexure II). The anonymity of the participants was maintained.

\subsection{Scheduling}

Data collection was scheduled in the month of February 2017.

\subsection{Sample size}

$\mathrm{N}=128$ ( $80 \%$ power at $5 \%$ alpha) based on the study done by Kumar Gaurav Chhabra et al [22] in the year 2014. Sample size was calculated using G- power. 


\subsection{Sampling}

A list of dental surgeons in Saveetha dental college, Chennai was obtained from the college administration. Following a simple random sampling, 132 practising dental house surgeons were enrolled in the study.

\subsection{Survey instrument}

A pre-tested, structured and self-administered questionnaire used in the survey tool consisted of three parts.

The first section collected demographic information of the participants such as name, age and gender.

The second part of the questionnaire consisted of 9 questions to assess the participant's levels of knowledge regarding mass disaster and its management followed by third part with 8 questions to assess the participant's attitude regarding mass disaster and its management.

This cross-sectional study was conducted with a 17 -item pretested, Self-administered questionnaire. The Cronbach's alpha and split validity scores for the questionnaire were 0.8 and 0.9 respectively. The final sample size was 132 after adjusting for a non-response rate of 10 percent.

\subsection{Survey methodology}

After a brief introduction on the purpose and intent of the study questionnaires were distributed to the dental house surgeons and filled questionnaires were collected. Only completely filled forms were considered for analysis.

\subsection{Statistical analysis}

Data was entered in Microsoft Excel spreadsheet and descriptive data in terms of frequency and percentage were analysed using SPSS software (Version 17.0).

\section{RESULTS}

Table 1 depicts the knowledge and awareness regarding mass disaster among the house surgeons. Among the house surgeons 12 (9.4\%) had poor knowledge, $72(56.3 \%)$ had fair knowledge and 44 (34.4\%) had good knowledge.

Table 1: Knowledge and awareness regarding mass disaster among the house surgeons.

\begin{tabular}{|c|c|c|}
\hline Knowledge Score & Frequency (n) & Percentage (\%) \\
\hline Poor (0-7) & 12 & 9.4 \\
\hline Fair (8-15) & 72 & 56.3 \\
\hline Good (16-23) & 44 & 34.4 \\
\hline Total & 128 & 100 \\
\hline
\end{tabular}


Table 2: Attitude and preparedness regarding mass disaster among the house surgeons.

\begin{tabular}{|c|c|c|}
\hline Attitude Score & Frequency (n) & Percentage (\%) \\
\hline Negative attitude (0-15) & 40 & 31.3 \\
\hline Positive attitude (16-31) & 88 & 68.8 \\
\hline Total & 128 & 100 \\
\hline
\end{tabular}

Table 3: Correlation between knowledge and attitude scores.

\begin{tabular}{|c|c|c|}
\hline \multicolumn{2}{|c|}{ Variables } & Attitude \\
\hline \multirow{3}{*}{ Knowledge } & $\begin{array}{l}\text { Spearman's } \\
\text { Correlation }\end{array}$ & $0.996^{* *}$ \\
\cline { 2 - 3 } & Sig. (2-tailed) & 0.000 \\
\cline { 2 - 3 } & $\mathrm{N}$ & 128 \\
\hline \multicolumn{2}{|c|}{$* *$ Correlation is significant at the 0.01 level (2-tailed). }
\end{tabular}

Table 2 depicts the attitude and preparedness regarding mass disaster among the house surgeons. Among the house surgeons $40(31.3 \%)$ had negative attitude and 88 (68.8\%) had positive attitude.

Table 3 depicts correlation between knowledge and attitude scores. The correlation between knowledge and attitude was found to be positive and the correlation was found to be significant statistically ( $>0.05$ ) using spearman's rho correlation. The positive correlation denotes that as the knowledge scores increased attitude scores increased.

\section{DISCUSSION}

In recent times, more number of natural and man-made disasters has been taking place in India. These occurrences have represented the lack of mass disaster preparedness among the medical professionals. Studies based on awareness and attitude towards mass disaster and its management has been conducted among various groups of health care professionals like pharmacists, nursing personnel, physiotherapists, members of alternative systems of medicine like Ayurveda, homeopathic medicine in various countries. Within the limitations of our literature review, only limited studies have been conducted among dental professionals.

There is insufficient literature and studies conducted among the dental house surgeon's population based on the awareness and attitude towards mass disaster and its management. The base line information from this study can be used to improve their awareness and attitude, as it urges them to gain more professional knowledge in this regard which will guide them to take part in the management of mass disasters. This study explores the awareness, attitude, and the various ways a dentist can get involved in the mass disaster management. 
Disaster management comprises of disaster response, disaster preparedness, and disaster mitigation [20], [21] regardless of the type of disasters or emergencies, dental professionals have the ability to treat injuries, control infection, manage patients, extract information from medical histories, administer injections, suture wounds, develop immunization procedures, prescribe drugs, provide triage services, and provide public information [6], [9]-[14].

In the present study, the level of knowledge has been categorized into three groups as poor, fair, and good. Categorization of knowledge scores was based on the scores obtained by the participants. Among the house surgeons 12 (9.4\%) had poor knowledge, 72 (56.3\%) had fair knowledge and $44(34.4 \%)$ had good knowledge. Findings were similar to the study conducted by Rajesh et al. [17], where $18.4 \%$ had poor knowledge, $68 \%$ had fair knowledge and $13.6 \%$ had good knowledge. Findings in the present study suggest that the knowledge scores of most of the participants were in the satisfactory level. Low scores of knowledge about disaster management were reported among Hawaiian dentists by Katz et al. [11], but higher scores were reported by Colvard et al. [16] among Illinois dentists. Dearth in the formal training programs about disaster management and the absence of disaster management in the undergraduate curriculum in India may have led to fair knowledge scores among the participants.

In the present study, attitude was categorized into positive and negative attitudes based on the scores obtained by the participants. Among the house surgeons $68.8 \%$ (88) house surgeons had a positive attitude and 31.3\% (40) house surgeons had a negative attitude. This response was similar to the study conducted by Chhabra et al. [22], where $73.79 \%$ had a fair attitude. A high attitude score among the respondents was a favourable sign, indicating that participants may be more willing regarding disaster management training. High attitude scores are a positive finding in the current study, as they can be used to improve knowledge and behaviour among the study subjects and also to execute various disaster management training measures in dental institution where this study was undertaken. This might develop the way for combining various resources toward efficient disaster management in India.

Among the 128 dental house surgeons, there was a positive correlation between knowledge and attitude scores (0.021), and the correlation was found significant statistically $(p<0.05)$ using spearman's rho correlation. The positive correlation denotes that, as the knowledge scores increased, attitude scores increased. Due to the lack of knowledge there is enormous number of deaths faced during the mass disasters. Awareness programs, if properly implemented, will lead to the improvement in the willingness to involve during the mass disasters which will help in efficiently and effectively manage all types of emergencies.

The occurrence of disasters in India has highlighted the inadequacies in disaster management and scarcity of health care professionals. O'Neill et al. [5] and Olson et al. [23] have observed that disaster management involves coordination and cooperation of professionals among different geographic and governmental jurisdictions. The integration of these various jurisdictions may be crucial for effective disaster management in India. Dental professionals represent an untapped and often overlooked resource. They can effectively complement the healthcare delivery system in disaster management efforts. The findings of the present study emphasize the need to incorporate disaster management in the undergraduate dental curriculum. This will mutually reinforce the medical training that dental students receive [24], thus enriching their learning experience. Training in general surgery, oral and maxillofacial surgery, microbiology, and pharmacology might contribute to appropriate management of infections, wound management and suturing, prescription of 
medications, infection control, managing victim triage and tagging, and patient management, immunization procedures, and distribution of medicines during disasters.

This study provides valuable baseline data to plan and implement various disaster management training programs in the dental scenario in India. "Standard Operating Procedures for Responding to Natural disasters (2010)" has recently been put forth by the Government of India [25].

Following a coordinated, horizontal approach for disaster management including varied sectors would be more beneficial than the narrow, vertical approach involving few sectors. There is a definite need for multidisciplinary approach to manage mass disasters in India.

Based on the finding of the study, there is difference in the levels of awareness and attitude towards mass disaster and its management among the participants and thus the null hypothesis is rejected.

Nevertheless, this present study has some limitations including that it had consisted of a small, selected sample size. So, the results cannot be generalized to all of society. As all the respondents were being trained according to a common curriculum, there may not have been any differences across the demographic variables. Also, biases would need to be considered, such as acquiescence or yea saying bias; deviation or faking bad bias; social desirability or faking good bias; the halo effect; positive skew; and end-aversion bias [26]. Further studies involving larger samples would be essential to clarify this finding.

However, the results are valuable because this study was first to be conducted in among dental house surgeons in Chennai. The study presents more findings which could be used to understand better and develop relevant awareness activities regarding mass disaster management.

\section{CONCLUSION}

Based on the findings of this study, it can be concluded that sufficient knowledge and awareness will bring in the enhanced contributions of dentists in mass disaster management. With considerable undergraduate dental students graduating every year from various dental institutions across India, integrating dental workforce into disaster management might be of greater importance.

Our study stresses that incorporation of mass disaster management programs in the dental under-graduate curriculum will help in an efficient and effective management of various mass disasters.

\section{REFERENCES}

[1] News article on typhoon in Philippines, Online. http://newsinfo.inquirer.net/492069/ powerful-typhoon-hits-taiwan-philippines. Accessed on: 12 Mar. 2017.

[2] Boslaugh, S., Encyclopaedia of Epidemiology, SAGE Publications: Los Angeles, CA, 2008.

[3] Colvard, M.D., Lampiris, L.N. \& Cordell, G.A., The dental emergency responder: expanding the scope of dentistry. Journal of American Dental Association, 137, pp. 468-473, 2006.

[4] Government of India, Ministry of Home Affairs, Disaster Management Division. Standard Operating Procedures for Responding to Natural Disasters, New Delhi, India, 2010.

[5] O’Neill, P.A., The ABCs of disaster response. Scandinavian Journal of Surgery, 94, pp. 259-266, 2005. 
[6] More, F.G., Phelan, J. \& Boylan, R., Predoctoral dental school curriculum for catastrophe preparedness. Journal of Dental Education, 68(8), pp. 851-858, 2004.

[7] Janssen, J. \& Lampiris, L.N., Disaster response in Illinois: the role for dentists and dental hygienists. Dental Clinics of North America, 51(4), pp. 779-784, 2007.

[8] Bethesda, M.D., National Institute of Dental and Craniofacial Research. Dentistry's Role in Responding to Bioterrorism and Other Catastrophic Events, 2011, Online. http://www.nidcr.nih.gov/careers and training/dentistrycatastrophicevents.htm. Accessed on: 12 Mar. 2017.

[9] Jeffcoat, M.K., Are we ready? Thinking about the unthinkable. Journal of American Dental Association, 133, pp. 1600-1604, 2002.

[10] Rekow, E.D., The dental team: a ready reserve or an overlooked resource? Journal of American Dental Association, 137, pp. 432-434, 2006.

[11] Katz, A.R., Nekorchuk, D.M., Holck, P.S., Hendrickson, L.A., Imrie, A.A. \& Effler, P.V., Dentists' preparedness for responding to bioterrorism: a survey of Hawaii dentists. Journal of American Dental Association, 137, pp. 461-467, 2006.

[12] Glick, M., Vaccines, epidemics, pandemics and us. Journal of American Dental Association, 137, pp. 706-708, 2006.

[13] Guay, A.H., The role dentists can play in mass casualty and disaster events. Dental Clinics of North America, 51(4), pp.767-778, 2007.

[14] Psoter, W.J., Park, P.J., Boylan, R.J., Morse, D.E. \& Glotzer, D.L., National emergency response programs for dental health care professionals. Journal of American Dental Association, 139, pp. 1067-1073, 2008.

[15] Galligan, J.M., Dentists can contribute expertise in a major public health disaster. Journal of the California Dental Association, 32(8), pp. 701-708, 2004.

[16] Colvard, M.D., Naiman, M.I., Mata, D., Cordell, G.A. \& Lampiris, L., Disaster medicine training survey results for dental health care providers in Illinois. Journal of American Dental Association, 138(4), pp. 519-524, 2007.

[17] Rajesh, G., Chhabra, K.G., Shetty, P.J., Prasad, K.V.V. \& Javali, S.B., A survey on disaster management among postgraduate students in a private dental institution in India. American Journal of Disaster Medicine, 6(5), pp. 309-318, 2011.

[18] Dental Council of India. New Delhi, India: Government of India, Online. http:// www.dciindia.org/. Accessed on: 14 Mar. 2017.

[19] Coule, P.L. \& Horner, J.A., National disaster life support programs: a platform for multi-disciplinary disaster response. Dental Clinics of North America, 51(4), pp. 819825, 2007.

[20] Park, K., Disaster management. Park K Preventive and Social Medicine, 22, Banarsidas Bhanot Publishers: Jabalpur (MP), India, pp. 740, 2013.

[21] Structuring health disaster management. Natural Disasters, Protecting the Public's Health. Washington, DC: Pan American Health Organization, 2000. Scientific Publication No. 575:11.

[22] Chhabra K.G., Rajesh G.R., Shetty P.J., Prasad K.V.V., Chhabra C. \& Muddapur M., Disaster Management Among Dental Graduates in a Private Dental Institution in India: A Pilot Study. Disaster Medicine and Public Health Preparedness, 8(1), pp. 37-43, 2014.

[23] Olson, D., Leitheiser, A., Atchison, C., Larson, S. \& Homzik, C., Public health and terrorism preparedness: cross-border issues. Public Health Reports.

[24] Psoter, W.J., Herman, N.G. \& More, F.G., Proposed educational objectives for hospital-based dentists during catastrophic events and disaster response. Journal of Dental Education, 70(8), pp. 835-843, 2006. 
[25] Government of India, Ministry of Home Affairs, Disaster Management Division. Standard Operating Procedures for Responding to Natural Disasters. New Delhi, India, 2010.

[26] Streiner, D.L. \& Norman, G.R., Biases in responding. PDQ Statistics, Oxford University Press: Oxford, England, 1995. 